\title{
The role of pemetrexed in recurrent epithelial ovarian cancer: A scoping review
}

\author{
Michael Roche, ${ }^{1}$ Laura Parisi, ${ }^{2}$ Linda Li, ${ }^{1}$ Amy Knehans, ${ }^{3}$ Rebecca Phaeton, ${ }^{4}$ Joshua P. Kesterson ${ }^{4}$ \\ ${ }^{1}$ Department of Obstetrics and Gynecology, Penn State Hershey Medical Center, Hershey, Pennsylvania; ${ }^{2}$ Department \\ of Obstetrics and Gynecology, The University of Kansas Medical Center, Kansas City, Kansas; ${ }^{3}$ Harrell Health \\ Sciences Library, Penn State College of Medicine, Hershey, Pennsylvania; ${ }^{4}$ Division of Gynecologic Oncology, Penn \\ State Hershey Medical Center, Hershey, Pennsylvania, USA
}

\begin{abstract}
Ovarian cancer is the leading cause of mortality among gynecologic malignancies, with most cases diagnosed at an advanced stage. Despite an initial response, most develop a recurrence and subsequent resistance to standard therapies. Pemetrexed (Alimta ${ }^{\mathrm{TM}}$ ) is a new generation multi-targeted antifolate initially approved for the treatment of malignant pleural mesothelioma. In recent years, it has shown promise in the treatment of recurrent epithelial ovarian cancer. In this review, we outline the current literature and discuss the future of pemetrexed in the setting of recurrent epithelial ovarian cancer.
\end{abstract}

\section{Introduction}

Ovarian cancer is the leading cause of mortality among gynecologic malignancies, with more than 22,000 new diagnoses and 14,000 deaths estimated to occur in $2017 .{ }^{1}$ Most cases are diagnosed at advanced stages, which carry worse prognoses. ${ }^{2}$ Initial treatment consists of a combination of surgery and chemotherapy, to which most patients experience an objective response. ${ }^{3}$ Despite

Correspondence: Michael Roche, Department of Obstetrics and Gynecology, Penn State Hershey Medical Center, 500 University Drive, Hershey, PA 17033, USA.

Tel.: +1.717.531.5394 - Fax: +1.717.531.0007

E-mail: mroche@pennstatehealth.psu.edu

Key words: Pemetrexed; Alimta; recurrent epithelial ovarian cancer; fallopian tube cancer; primary peritoneal cancer.

Contributions: the authors contributed equally.

Conflicts of interest: the authors have no conflicts of interest to disclose.

Received for publication: 3 December 2017.

Revision received: 26 January 2018.

Accepted for publication: 14 February 2018.

This work is licensed under a Creative Commons Attribution NonCommercial 4.0 License (CC BY-NC 4.0).

CCopyright M. Roche et al., 2018

Licensee PAGEPress, Italy

Oncology Reviews 2018; 12:346

doi:10.4081/oncol.2018.346 an initial response, most patients recur. Those who develop recurrence more than six months after therapy are classified as platinum-sensitive, while those who develop recurrence before six months are deemed platinum-resistant. Prognosis for platinumresistant disease is poor. Available treatment options for platinum resistant disease include paclitaxel, pegylated liposomal doxorubicin, gemcitabine, and topotecan. Response rates for platinumresistant disease are poor. ${ }^{4-9}$ Novel therapeutic approaches are needed to improve outcomes for patients with recurrent platinum resistant epithelial ovarian cancer.

Pemetrexed is a new generation multi-targeted antifolate agent which was initially approved by the FDA in 2004 for the treatment of malignant pleural mesothelioma in combination with cisplatin. ${ }^{10}$ It has also demonstrated activity against several tumor types, including ovarian cancer, both as a single agent and when combined with other cytotoxic agents. ${ }^{11-12}$

Recent guidelines from the National Comprehensive Cancer Center Network (NCCN) include pemetrexed as a single agent for women with recurrent ovarian cancer who demonstrate platinum resistant disease. ${ }^{13}$

The purpose of this scoping review is to address the gaps in the published literature regarding the efficacy of pemetrexed, alone and in combination, as a treatment option for women with recurrent ovarian cancer.

\section{Research methods}

Scoping reviews are conducted in order to map the key concepts in an area of research and identify the sources and types of available evidence. We used the five-step method for scoping reviews developed by Arksey and O'Malley. ${ }^{14}$

1. The research question. Our research question is: what is the current state of pemetrexed as therapy in the setting of recurrent ovarian cancer? As of this writing, multiple systematic reviews are published discussing pemetrexed, its clinical activity and toxicity profile in recurrent ovarian cancer. We believe a review of the available clinical trials and existing literature would add a greater understanding of pemetrexed and underscore the need for further investigation of it as treatment of recurrent ovarian cancer.

2. Identify relevant studies. We performed an electronic literature search using the following databases and web-based searches: MEDLINE, Cochrane Library, ClinicalTrials.gov, Canadian Clinical Trials and Cancer Trials, Australian Clinical Trials, WHO ICTRP, and Google Scholar. We used the MeSH terms 'ovarian neoplasms', 'pemetrexed,' 'fallopian tube neoplasms' while using MEDLINE. In other search engines, we used combinations of 'ovarian cancer', 'primary peritoneal cancer', 'pemetrexed', 
'Alimta', 'multitargeted antifolate', and 'LY231514'. We only included English-language publications and studies with humans as subjects. This strategy yielded 26 results. These search results are current as of November 24, 2017.

3. Study selection. Studies were initially selected if the topic was pemetrexed therapy in ovarian cancer, making sure to filter out research pertaining to the topics of mesothelioma and lung cancer, as the bulk of pemetrexed literature pertains to these diseases. We included studies that had results pertaining to pemetrexed and its effects in the setting of recurrent ovarian cancer. Duplicate results, studies without dose schedules, and trials without evidence were excluded. Two members of the research team independently applied inclusion and exclusion criteria. Of the 26 results, ten were excluded for not meeting criteria. The primary reasons for exclusion were that the studies did not have available results or were about unrelated topics. Of the remaining 16 results, five were phase I trials, five were phase II trials, five were systematic reviews, and one was an expert commentary.

4. Charting the data. We recorded the following data from the selected studies on a data extraction sheet: author, year of publication, Clinical Trials Identifier (if applicable), treatment regimen (if applicable), study design, study population and size (if applicable), and study outcome.

5. Collating, summarizing, and reporting results. Drafts of this manuscript were circulated and edited based on feedback from the study team until it appropriately reflected the results of the literature search.

\section{Results}

We identified 16 studies meeting criteria. They are listed in Tables 1-4. ${ }^{4,20-28,31-36}$

Table 1. Phase I studies.

\begin{tabular}{|c|c|c|c|c|c|}
\hline Author & Year & Study population & Study size & Treatment* & Conclusion \\
\hline Misset $^{20}$ & 2004 & $\begin{array}{l}\text { Locally advanced or } \\
\text { metastatic solid tumors }\end{array}$ & 45 (including 3 ovarian) & $\begin{array}{l}\text { Escalating dose pemetrexed and } \\
\text { oxaliplatin without supplementation, } \\
\text { 21-day cycle }\end{array}$ & $\begin{array}{l}\text { MTD of pemetrexed was } \\
\text { not reached. } \\
\text { The recommended phase II dose } \\
\text { was } 500 \mathrm{mg} / \mathrm{m}^{2} \text { plus oxaliplatin } 120 \mathrm{mg} / \mathrm{m}^{2}\end{array}$ \\
\hline Hensley $^{21}$ & 2008 & $\begin{array}{l}\text { Solid tumor cohort } \\
\text { and recurrent } \mathrm{OC} \text { cohort }\end{array}$ & 54 (including 30 ovarian) & $\begin{array}{l}\text { Escalating dose pemetrexed + } \\
\text { gemcitabine, 14-day cycle }\end{array}$ & $\begin{array}{l}\text { In OC patients, the MTD for pemetrexed } \\
\text { was } 600 \mathrm{mg} / \mathrm{m}^{2}\end{array}$ \\
\hline Sehouli22 & 2010 & $\begin{array}{l}\text { Platinum sensitive } \\
\text { recurrent } \mathrm{OC}\end{array}$ & 20 & $\begin{array}{l}\text { Escalating dose pemetrexed + } \\
\text { escalating dose carboplatin, } \\
\text { 21-day cycle }\end{array}$ & $\begin{array}{l}\text { MTD was not reached for either } \\
\text { medication. The recommended phase II } \\
\text { dose for pemetrexed was } 500 \mathrm{mg} / \mathrm{m}^{2} \\
\text { and carboplatin AUC } 6\end{array}$ \\
\hline Richards $^{23}$ & 2011 & $\begin{array}{l}\text { Refractory OC, } \\
\text { breast cancer, } \\
\text { peritoneal cancer }\end{array}$ & $\begin{array}{l}29 \text { (including } 16 \text { ovarian, } \\
3 \text { primary peritoneal, } \\
10 \text { breast) }\end{array}$ & $\begin{array}{l}\text { Escalating dose pemetrexed } \\
\text { (days } 1,15)+ \text { escalating dose } \\
\text { PLD (day 1), 28-day cycle }\end{array}$ & $\begin{array}{l}\text { MTD of pemetrexed was } 500 \mathrm{mg} / \mathrm{m}^{2} \text { and } \\
\text { MTD of PLD was } 40 \mathrm{mg} / \mathrm{m}^{2}\end{array}$ \\
\hline Chambers $^{2}$ & 42012 & Stage III OC & 15 & $\begin{array}{l}\text { Escalating dose IP pemetrexed + } \\
\text { cisplatin + paclitaxel, 21-day cycle }\end{array}$ & MTD of pemetrexed was $500 \mathrm{mg} / \mathrm{m}^{2}$ \\
\hline
\end{tabular}

${ }^{*}$ Given intravenously unless otherwise noted. Vitamin B12 and folate supplementation given unless otherwise noted. IP, intraperitoneal; MTD, maximum tolerated dose; OC, ovarian cancer; PLD, pegylated liposomal doxorubicin.

Table 2. Phase II studies.

\begin{tabular}{|c|c|c|c|c|c|}
\hline Author & Year & Study population & Study size & Treatment* & Outcome \\
\hline Miller ${ }^{25}$ & 2009 & $\begin{array}{l}\text { Platinum resistant } \\
\text { recurrent } \mathrm{OC}\end{array}$ & 51 & $\begin{array}{l}\text { Pemetrexed } 900 \mathrm{mg} / \mathrm{m}^{2} \text {, } \\
\text { 21-day cycle }\end{array}$ & $\begin{array}{l}\text { The overall response rate of pemetrexed } \\
\text { in this population was } 21 \% \text {. } \\
\text { One patient had a complete response. } \\
\text { The toxicity profile was mild }\end{array}$ \\
\hline Vergote $^{26}$ & 2009 & $\begin{array}{l}\text { Platinum resistant } \\
\text { recurrent } \mathrm{OC}\end{array}$ & $\begin{array}{l}98 \text { (47 given } 500 \mathrm{mg} / \mathrm{m}^{2} \\
51 \text { given } 900 \mathrm{mg} / \mathrm{m}^{2} \text { ) }\end{array}$ & $\begin{array}{l}\text { Pemetrexed } 500 \mathrm{mg} / \mathrm{m}^{2} \\
\text { or } 900 \mathrm{mg} / \mathrm{m}^{2}, 21 \text {-day cycle }\end{array}$ & $\begin{array}{l}\text { The response rate was } 9.3 \% \text { for those } \\
\text { given } 500 \mathrm{mg} / \mathrm{m}^{2} \text { and } 10.4 \% \text { for patients } \\
\text { given } 900 \mathrm{mg} / \mathrm{m}^{2} \text {. The higher dose did not } \\
\text { significantly improve response. } \\
\text { Therapy was better tolerated at } 500 \mathrm{mg} / \mathrm{m}^{2}\end{array}$ \\
\hline Sehouli $^{27}$ & 2012 & $\begin{array}{l}\text { Platinum sensitive } \\
\text { recurrent } \mathrm{OC}\end{array}$ & 61 & $\begin{array}{l}\text { Pemetrexed } 500 \mathrm{mg} / \mathrm{m}^{2}+ \\
\text { carboplatin AUC } 6, \\
\text { 21-day cycle }\end{array}$ & $\begin{array}{l}\text { Overall response rate for this study was } 32.8 \% \text {, } \\
\text { with one patient experiencing a complete response. } \\
\text { This combination demonstrated little serious toxicity }\end{array}$ \\
\hline Matulonis ${ }^{28}$ & 2008 & $\begin{array}{l}\text { Platinum sensitive } \\
\text { recurrent } \mathrm{OC}\end{array}$ & 45 & $\begin{array}{l}\text { Pemetrexed } 500 \mathrm{mg} / \mathrm{m}^{2}+ \\
\text { carboplatin AUC } 6, \\
\text { 21-day cycle }\end{array}$ & $\begin{array}{l}\text { The response rate for this pair was } 51.1 \% \text {, } \\
\text { with no complete responses. } \\
\text { It exhibited an acceptable toxicity profile }\end{array}$ \\
\hline Hagemann $^{31}$ & 2013 & $\begin{array}{l}\text { Platinum resistant } \\
\text { and platinum sensitive } \\
\text { recurrent } \mathrm{OC}\end{array}$ & 34 & $\begin{array}{l}\text { Pemetrexed } 500 \mathrm{mg} / \mathrm{m}^{2}+ \\
\text { bevacizumab } 15 \mathrm{mg} / \mathrm{kg} \\
\text { 21-day cycle }\end{array}$ & $\begin{array}{l}\text { The overall response rate was } 41 \% \text {, } \\
\text { with no complete responses. One patient with } \\
\text { platinum-sensitive disease developed acute } \\
\text { myeloid leukemia, possibly related to therapy }\end{array}$ \\
\hline
\end{tabular}

*Given intravenously. All studies used vitamin supplementation. OC, ovarian cancer; RR, response rate; CR, complete response. 


\section{Optimal dose and toxicity}

The optimal dosing of pemetrexed was first explored in trials focusing on non-small cell lung cancer. This was found to be 500 $\mathrm{mg} / \mathrm{m}^{2}$, as higher doses were accompanied by more severe side effects, usually gastrointestinal upset and myelosuppression. ${ }^{15,16}$ Further research demonstrated that elevated pretreatment levels of homocysteine and methylmalonic acid place a patient at higher risk for severe pemetrexed toxicity. Pretreatment with vitamin B12 and folic acid reduced severe neutropenia and myelosuppression. ${ }^{17,18}$ Vitamin supplementation has not been shown to adversely impact pemetrexed activity, ${ }^{19}$ and as such it is now standard when administering pemetrexed.

\section{Phase I trials}

Initial studies determining the maximal tolerated dose (MTD) of pemetrexed, in combination with other cytotoxic therapies, in the setting of ovarian cancer have been conducted. Misset et al. administered pemetrexed and oxaliplatin every 21 days to 36 patients (5 of whom had a gynecologic malignancy), in a doseescalation regimen starting at pemetrexed $300 \mathrm{mg} / \mathrm{m}^{2}$ and oxaliplatin $85 \mathrm{mg} / \mathrm{m}^{2}$. There were no dose limiting toxicities (DLTs) observed at dosages up to pemetrexed $500 \mathrm{mg} / \mathrm{m}^{2}$ plus oxaliplatin $120 \mathrm{mg} / \mathrm{m}^{2} .{ }^{20}$ A study including 24 patients with recurrent ovarian cancer treated with pemetrexed in a dose escalation protocol starting at $300 \mathrm{mg} / \mathrm{m}^{2}$ plus gemcitabine $1,500 \mathrm{mg} / \mathrm{m}^{2}$ with Vitamin B12 and folic acid supplementation demonstrated the MTD was 600 $\mathrm{mg} / \mathrm{m}^{2}{ }^{21}$ The most common toxicities were hematologic, including neutropenia. A study by Sehouli and colleagues sought to determine the MTD of pemetrexed, this time in combination with carboplatin, in a similar dose escalation schema in 20 platinumsensitive ovarian cancer patients. ${ }^{22}$ Over 100 cycles were administered, with one DLT at pemetrexed $600 \mathrm{mg} / \mathrm{m}^{2}+$ carboplatin AUC 6 , and no serious adverse events observed. In a subsequent study of 29 patients, a majority of whom had recurrent ovarian, fallopian tube, or peritoneal cancer, pemetrexed $500 \mathrm{mg} / \mathrm{m}^{2}$ and pegylated liposomal doxorubicin (PLD) $40 \mathrm{mg} / \mathrm{m}^{2}$ administered every 28 days, with vitamin $\mathrm{B}_{12}$ and folic acid supplementation, was tolerated with a similar toxicity profile (e.g. neutropenia, thrombocytope- nia, anemia). ${ }^{23}$ In a novel approach by investigators at the University of Arizona, pemetrexed was administered intraperitoneally (IP) in a dose escalation fashion with intraperitoneal cisplatin and paclitaxel. ${ }^{24}$ Fifteen patients were enrolled and treated. Of the three treated with $1000 \mathrm{mg} / \mathrm{m}^{2}$ pemetrexed, two patients experienced DLTs (one pancytopenia who eventually recovered, one death from opportunistic infection). The median progressionfree survival was 30.1 months. Patients receiving $500 \mathrm{mg} / \mathrm{m}^{2}$ pemetrexed in combination with standard doses of IP cisplatin and paclitaxel showed a favorable toxicity profile. The MTD dose was suggested to be $500 \mathrm{mg} / \mathrm{m}^{2}$, however further investigation of IP pemetrexed was deemed warranted.

\section{Phase II trials - single therapy}

Two trials have explored single agent pemetrexed as treatment for recurrent ovarian cancer. ${ }^{25,26}$ In these trials, the primary outcome assessed was response rate.

Miller and colleagues administered intravenous pemetrexed to 48 patients at a dose of $900 \mathrm{mg} / \mathrm{m}^{2}$ as single therapy every 21 days until disease progression or unacceptable adverse events. More than 250 cycles were given. The overall response rate was $21 \%$, with one patient experiencing a complete response. The most common grade 3 and 4 toxicities were hematologic. They reported no treatment related deaths. Vergote et al. compared high $\left(900 \mathrm{mg} / \mathrm{m}^{2}\right)$ and low $\left(500 \mathrm{mg} / \mathrm{m}^{2}\right)$ dose intravenous pemetrexed in recurrent ovarian cancer. Ninety-eight patients were evaluable for toxicity, with 47 receiving low dose and 51 receiving high dose therapy. The response rate $(9.3 \%$ for low dose; $10.4 \%$ for high dose) and median progression-free survival (PFS) (11.9 months; 10.3 months) were comparable. However, treatment with high dose therapy demonstrated more serious drug related adverse events, including two deaths possibly related to treatment complications. Given the above, the study's authors recommended low dose therapy $\left(500 \mathrm{mg} / \mathrm{m}^{2}\right)$ as standard treatment.

\section{Phase II trials - combination therapy}

Multiple phase two trials have been conducted with pemetrexed as combination therapy in patients with recurrent ovarian

Table 3. Reviews.

\begin{tabular}{|c|c|c|c|}
\hline Author & Year & Conclusion & Comments \\
\hline Tomao $^{4}$ & 2009 & $\begin{array}{l}\text { Continued exploration of pemetrexed and other } \\
\text { cytotoxic agents/targeted therapies is warranted in recurrent OC }\end{array}$ & \\
\hline Morotti ${ }^{33}$ & 2012 & $\begin{array}{l}\text { Pemetrexed appears to have similar clinical activity in ovarian } \\
\text { cancer compared to current therapies. Further pharmacogenomic } \\
\text { and clinical trial data are warranted to better define the role } \\
\text { of pemetrexed in recurrent OC. }\end{array}$ & \\
\hline Miller $^{34}$ & 2013 & $\begin{array}{l}\text { Pemetrexed shows activity in ovarian and cervical cancers } \\
\text { with tolerable side effect profile, warrants further study }\end{array}$ & $\begin{array}{l}\text { Included patient series of } 13 \text { patients who received } \\
\text { pemetrexed for recurrent OC. Treatments were well }\end{array}$ \\
\hline Egloff ${ }^{35}$ & 2014 & $\begin{array}{l}\text { Pemetrexed demonstrates efficacy in both recurrent } \\
\text { and primary OC, warrants further investigation. }\end{array}$ & $\begin{array}{l}\text { tolerated with a median OS of } 4.8 \text { months. } \\
\text { No dose/schedule available on cohort. }\end{array}$ \\
\hline Smith $^{36}$ & 2004 & $\begin{array}{l}\text { Preliminary findings in ovarian cancer also indicate activity } \\
\text { of pemetrexed in this setting. Ongoing and planned studies will help } \\
\text { to establish the optimal uses and role of pemetrexed in gynecologic cancers. }\end{array}$ & \\
\hline
\end{tabular}

OC, ovarian cancer.

Table 4. Expert commentary.

\begin{tabular}{llll} 
Author & Year & Study design & Conclusion \\
Ledermann & & & \\
\hline
\end{tabular}


cancer. Two such trials compared intravenous pemetrexed in combination with carboplatin, both in platinum-sensitive disease. ${ }^{27,28}$ This combination has been shown to be effective in the setting of advanced breast cancer and non-small cell lung cancer. ${ }^{29,30}$

Matulonis et al. administered carboplatin AUC 5 and pemetrexed $500 \mathrm{mg} / \mathrm{m}^{2}$ every 21 days to 44 patients for a total of 235 cycles. Response rate was $51.1 \%$, with no complete responses. Median PFS was 7.57 months. Thirteen patients required dose reduction for toxicity. Eight patients were prescribed myeloid growth factor support. No other serious adverse events were reported. Carboplatin AUC 6 and pemetrexed $500 \mathrm{mg} / \mathrm{m}^{2}$ given every 21 days were studied by Sehouli and colleagues. Sixty-six patients were treated, and 61 were evaluable. Twenty patients (32.8\%) experienced a response, with one of those patients experiencing a complete response. The median PFS was 9.4 months. One patient died due to multiple organ failure, possibly related to chemotherapy. The authors independently conclude that this combination should be used in randomized testing against other therapies for recurrent epithelial ovarian cancer given its acceptable side effect profile and response rates comparable to standard therapies.

Another trial by Hageman studied dual therapy with pemetrexed $500 \mathrm{mg} / \mathrm{m}^{2}$ and bevacizumab $15 \mathrm{mg} / \mathrm{kg}$ in 34 patients with recurrent epithelial ovarian, fallopian tube, or primary peritoneal cancer. ${ }^{31}$ Therapy was given every 21 days. Women with both platinum sensitive and platinum resistant disease were included. Response rate for the entire population was $41 \%$, with zero complete responses. Median PFS was 7.9 months, and median overall survival (OS) was 25.7 months. Two patients eventually developed hematologic malignancies. One patient developed acute myeloid leukemia (AML) and recovered after therapy and stem cell transplant. The other patient developed myelodysplastic syndrome.

\section{Reviews and editorials}

In 2009, an editorial was published in the European Journal of Cancer highlighting the need for further research on pemetrexed as therapy in ovarian cancer. ${ }^{32}$ As of this writing, five reviews have been published on this topic, most recently in 2014.,43-36 Each review separately highlights both the clinical efficacy and tolerable side effect profile of pemetrexed. The studies conclude that while the current literature presents pemetrexed as a promising therapy for recurrent ovarian cancer with a favorable side effect profile, the lack of phase III trials comparing its clinical activity to current accepted treatments prohibits its use in these patients.

\section{Future directions}

With the limited efficacy of a nondiscriminatory approach to treatment with pemetrexed there may be a role for a directed approach based on mutational analysis, as has been tested in other tumor types. Thymidylate synthase (TS), an enzyme inhibited by pemetrexed, has been studied most extensively. In a phase II trial of pemetrexed treatment for advanced breast cancer by Gomez et al., the correlation between TS levels in surgical specimens and clinical response was evaluated. ${ }^{37}$ Patients with lower tumor TS levels at baseline were more likely to respond to pemetrexed than those with higher levels. Subsequent studies in other tumor types, including non-small cell lung cancer and mesothelioma, have demonstrated a similar relationship. ${ }^{38-43}$ Other tumor-expressed markers such as miR-25, miR-145, miR-210, thyroid transcription factor 1 , and serum leptin have been studied as potential predictors of pemetrexed response. ${ }^{42,44,45}$ In their Phase II trial of pemetrexed in platinum resistant ovarian cancer, Vergote et al. showed low levels of both reduced folate carrier (RFC) and excision repair crosscomplementation group 1 (ERCC1) were associated with improved outcomes. ${ }^{26}$ While these results are intriguing, additional investigations are needed to verify these markers in the clinical setting. We are not aware of any other studies evaluating the correlation between an ovarian cancer expression profile and pemetrexed response.

Currently, one phase II clinical trial (NCT01001910) studying pemetrexed and carboplatin in the setting of recurrent ovarian cancer is completed and awaiting final results. ${ }^{46}$ Two trials are recruiting as of this writing: a phase I trial using bosutinib in combination with pemetrexed in patients with selected metastatic solid tumors (NCT03023319) and a phase I study of methoxyamine in combination with cisplatin and pemetrexed in patients with advanced non-small cell lung cancer, mesothelioma, thymoma, and ovarian cancer (NCT02535312). ${ }^{47,48}$

\section{Discussion}

Pemetrexed enters the cell through a folate receptor system, folate receptor alpha $(\mathrm{FR} \alpha)$, which has been shown to be overexpressed in multiple solid cancer lines, including ovarian. Moreover, its expression correlates with the severity of the disease. ${ }^{12,49}$ It disrupts folate-dependent metabolic processes essential for nucleic acid synthesis. Thus, it acts with greatest effect on rapidly growing cells. Unlike other antifolate agents, pemetrexed exerts effects on multiple enzymes. It is an antimetabolite that inhibits thymidylate synthase (TS), dihydrofolate reductase (DHFR), glycinamide ribonucleotide formyltransferase (GARFT), and 5-aminoimidazole-4-carboxamide ribonucleotide formyltransferase (AICARFT)..$^{50,51}$ It is similar to methotrexate in its activity against DHFR and it is similar to 5-fluorouracil in its activity against TS. GARFT and AICARFT are two enzymes in the pathway of purine synthesis not currently targeted by antineoplastic agents. ${ }^{52,53}$

The efficacy of pemetrexed in other solid tumors has been previously described. Pemetrexed and cisplatin have become standard therapy for patients with nonresectable malignant pleural mesothelioma (MPM) based on a phase III trial by Vogelzang comparing combination pemetrexed/cisplatin with single agent cisplatin. ${ }^{19}$ The combination cohort showed a better response rate $(41.3 \%$ vs $16.7 \%$ in control, $\mathrm{P}<0.0001)$. It also demonstrated significantly improved median survival time (12.1 vs 9.3 months, $\mathrm{P}=0.020)$ and longer median time to progression (5.7 months vs 3.9 months, $\mathrm{P}=0.001$ ). Encouraged by these results, pemetrexed has been studied in the setting of other solid tumor types, including epithelial ovarian cancer. Response rates in phase II trials are comparable to the current standards utilized in both platinum-sensitive and platinum-resistant recurrent disease with a favorable side effect profile (Table 2). Despite these promising early trials, its efficacy in recurrent ovarian cancer requires further study.

While most patients initially respond to first-line therapy for ovarian cancer, most will experience a recurrence. Many agents are currently used for treatment of these recurrences. However, most offer a low response rate. These treatments are rarely curative and offer a median survival of only two years. ${ }^{4}$ Pemetrexed is a newer cytotoxic agent that has drawn interest given its activity in several different solid tumor types. Its biochemical pathways are well-documented. It offers a favorable toxicity profile and it has response rates comparable to other agents used in first-line combination in GOG $182,{ }^{54}$ suggesting it can be used as a leading therapy in this setting. It has been most extensively studied at a dose of 500 $\mathrm{mg} / \mathrm{m}^{2}$ administered every 21 days with vitamin supplementation.

This review highlighted the possible utility of biomarkers. Their potential role to assess the effectiveness of pemetrexed in 
recurrent ovarian cancer is intriguing, especially given recent increased interest in pharmacogenomics. Despite the promise of ERCC1 and RFC as predictors of response to pemetrexed in recurrent ovarian cancer, additional research is paramount to validate their routine use. Furthermore, although thymidylate synthase has been studied extensively as a biomarker in non-small cell lung cancer, this analysis has not begun in ovarian cancer. The field of biomarkers to predict response is an emerging one. Preliminary data warrant further study of these biomarkers for pemetrexed in various tumor types.

\section{Conclusions}

The purpose of this review was to address the knowledge gaps in the current published literature regarding the efficacy of pemetrexed, alone and in combination, as a treatment option for women with recurrent ovarian cancer. We also hoped to highlight the need for phase III trials comparing this medication to current standard therapy. It is evident given the clinical efficacy and favorable toxicity profile of pemetrexed that further studies comparing it to current therapies for recurrent ovarian cancer are warranted. Response rates for platinum-resistant ovarian cancer have been historically poor. Targeted, novel agents are needed. Pemetrexed has shown responses in a typically chemoresistant population that warrant continued investigation. No published studies have directly compared pemetrexed to other treatments, and no studies are currently listed as recruiting to investigate this purpose. The likelihood of phase III clinical trials will be dependent on the outcomes of the pending phase I and phase II clinical trials. Future determination of its role awaits further investigation.

\section{References}

1. Siegel R. Cancer statistics. CA-Cancer J Clin 2017;67:7-30.

2. Rosenthal A, Menon U, Jacobs I. Screening for ovarian cancer. Clin Obstet and Gynecol 2006;49:433-47.

3. Jelovac D, Armstrong DK. Recent progress in the diagnosis and treatment of ovarian cancer. CA-Cancer J Clin 2011;61:183-203

4. Tomao F, Panici P, Frati L, Tomao S. Emerging role of pemetrexed in ovarian cancer. Expert Rev Anticanc 2009;9:1727-35.

5. Piccart M, Green J, Lacave A, et al. Oxaliplatin or paclitaxel in patients with platinum-pretreated advanced ovarian cancer: a randomized phase II study of the European Organization for Research and Treatment of Cancer Gynecology Group. J Clin Oncol 2000;18:1193-202.

6. Gordon A, Tonda M, Sun S, et al. Long-term survival advantage for women treated with pegylated liposomal doxorubicin compared with topotecan in a phase 3 randomized study of recurrent and refractory epithelial ovarian cancer. Gynecol Oncol 2004;95:1-8.

7. Meier W, du Bois A, Reuss A, et al. Topotecan versus treosulfan, an alkylating agent, in patients with epithelial ovarian cancer and relapse within 12 months following 1st-line platinum/paclitaxel chemotherapy. A prospectively randomized Phase III trial by the Arbeitsgemeinschaft Gynaekologische Onkologie Ovarian Cancer Study Group (AGO-OVAR). Gynecol Oncol 2009;114:199-205.

8. Mutch D, Orlando M, Goss T, et al. Randomized Phase III trial of gemcitabine compared with PEGylated liposomal doxorubicin in patients with platinum-resistant ovarian cancer. J Clin
Oncol 2007;25:2811-8.

9. Ferrandina G, Ludovisi M, Lorusso D, et al. Phase III trial of gemcitabine compared with pegylated liposomal doxorubicin in progressive or recurrent ovarian cancer. J Clin Oncol 2008;26:890-6.

10. Food and Drug Administration (FDA). Drug Facts Alimta 2012; Available from: http://www.accessdata.fda.gov/drugsatfda_docs/label/2012/021462s039lbl.pdf

11. Corona G, Giannini F, Fabris M, et al. Role of folate receptor and reduced folate carrier in the transport of 5-methyltetrahydrofolic acid in human ovarian carcinoma cells. Int J Cancer 1988;75:125-33.

12. Miotti S, Bagnoli M, Ottone F, et al. Simultaneous activity of two different mechanisms of folate transport in ovarian carcinoma cell lines. J Cell Biochem 1997;65:479-91.

13. NCCN Guidelines for Patients: Ovarian Cancer 2017; Available from: www.nccn.org/professionals/physician_gls/ PDF/ovarian.pdf

14. Arksey H, O'Malley L. Scoping studies: towards a methodological framework. Int J Soc Res Method 2005;8:19-32.

15. Rustsoven J, Eisenhauer E, Butts C, et al. Multitargeted antifolate, LY231514, as first-line chemotherapy for patients with advanced non-small-cell lung cancer: a phase II study National Cancer Institute of Canada Clinical Trials Group. J Clin Oncol 1999;17:1194-9.

16. Rinaldi D. Overview of phase I trials of multitargeted antifolate (MTA, LY231514). Semin Oncol 1999;23:82-8.

17. Niyikiza C, Baker S, Seitz D, et al. Homocysteine and methylmalonic acid: markers to predict and avoid toxicity from pemetrexed therapy. Mol Cancer Ther 2002;1:545-52.

18. Scagliotti G, Shin D, Kindler H, et al. Phase II study of pemetrexed with and without folic acid and vitamin B12 as frontline therapy in malignant pleural mesothelioma. J Clin Oncol 2003;21:1556-61.

19. Vogelzang N, Rusthoven J, Symanowski J, et al. Phase III study of pemetrexed in combination with cisplatin versus cisplatin alone in patients with malignant pleural mesothelioma. $\mathrm{J}$ Clin Oncol 2003;21:2636-44.

20. Misset J, Gamelin E, Campone M, et al. Phase I and pharmacokinetic study of the multitargeted antifolate pemetrexed in combination with oxaliplatin in patients with advanced solid tumors. Ann Oncol 2004; 15:1123-9.

21. Hensley M, Larkin J, Fury M, et al. A phase I trial of pemetrexed plus gemcitabine given biweekly with B-vitamin support in solid tumor malignancies or advanced epithelial ovarian cancer. Clin Cancer Res 2008;14:6310-6.

22. Sehouli J, Camara O, Mahner S, et al. A phase I trial of pemetrexed plus carboplatin in recurrent ovarian cancer. Cancer Chemoth Pharm 2010;68:861-8.

23. Richards D, Loesch D, Vukelja S, et al. A phase I study of pemetrexed and PEGylated liposomal doxorubicin in patients with refractory breast, ovarian, primary peritoneal, or fallopian tube cancer. Invest New Drugs 2011;29:963-70.

24. Chambers S, Chow H, Janicek M, et al. Phase I trial of intraperitoneal pemetrexed, cisplatin, and paclitaxel in optimally debulked ovarian cancer. Clin Cancer Res 2012;18:2668-78.

25. Miller D, Blessing J, Krasner C, et al. Phase II evaluation of pemetrexed in the treatment of recurrent or persistent platinum-resistant ovarian or primary peritoneal carcinoma: a study of the Gynecologic Oncology Group. J Clin Oncol 2009;27:2686-91.

26. Vergote I, Calvert H, Kania M, et al. A randomised, doubleblind, phase II study of two doses of pemetrexed in the treat- 
ment of platinum-resistant, epithelial ovarian or primary peritoneal cancer. Eur J Cancer 2009;45:1415-23.

27. Sehouli J, Alvarez A, Manouchehrpour S, et al. A phase II trial of pemetrexed in combination with carboplatin in patients with recurrent ovarian or primary peritoneal cancer. Gynecol Oncol 2011;124:205-9.

28. Matulonis U, Horowitz N, Campos S, et al. Phase II study of carboplatin and pemetrexed for the treatment of platinum-sensitive recurrent ovarian cancer. J Clin Oncol 2008;26:5761-6.

29. Garin A, Manikhas A, Biakhov M, et al. Phase II study of pemetrexed and carboplatin in patients with locally advanced or metastatic breast cancer. Breast Cancer Res Treat 2008;110:309-15.

30. Socinski M, Weissman C, Hart L, et al. Randomized phase II trial of pemetrexed combined with either cisplatin or carboplatin in untreated extensive-stage small-cell lung cancer. J Clin Oncol 2006;24:4840-7.

31. Hagemann A, Novetsky A, Zighelboim I, et al. Phase II study of bevacizumab and pemetrexed for recurrent or persistent epithelial ovarian, fallopian tube or primary peritoneal cancer. Gynecol Oncol 2013;131:535-40.

32. Ledermann J, Stebbing J. Positioning pemetrexed in the treatment of ovarian cancer. Eur J Cancer 2009;45:1330-2.

33. Morotti M, Valenzano Menada M, et al. Pemetrexed disodium in ovarian cancer treatment. Expert Opin Investig Drugs 2012; 21: 437-49.

34. Miller D, Tai D, Obasaju C, Vergote I. Safety and efficacy of pemetrexed in gynecologic cancers: a systematic literature review. Modern Chemother 2013;2:19-32.

35. Egloff H, Jatoi A. Pemetrexed for ovarian cancer: a systematic review of the published literature and a consecutive series of patients treated in a nonclinical setting. Case Rep Oncol 2014;7:541-9.

36. Smith I. Phase II studies of pemetrexed in metastatic breast and gynecologic cancers. Oncology (Williston Park) 2004;18:63-5.

37. Gomez H, Santillana S, Vallejos C, et al. A phase II trial of pemetrexed in advanced breast cancer: clinical response and association with molecular target expression. Clin Cancer Res 2006; 12:832-8.

38. Chamizo C, Zazo S, Dómine M, et al. Thymidylate synthase expression as a predictive biomarker of pemetrexed sensitivity in advanced non-small cell lung cancer. BMC Pulm Med 2015; $15: 132$.

39. Nicolson M, Fennell D, Ferry D, et al. Thymidylate synthase expression and outcome of patients receiving pemetrexed for advanced nonsquamous non-small-cell lung cancer in a prospective blinded assessment phase II clinical trial. J Thorac Oncol 2013;8:930-9.

40. Righi L, Papotti M, Ceppi P, et al. Thymidylate synthase but not excision repair cross-complementation group 1 tumor expression predicts outcome in patients with malignant pleural mesothelioma treated with pemetrexed-based chemotherapy. J Clin Oncol 2010;28:1534-9.
41. Sun J, Ahn J, Jung S, et al. Pemetrexed plus cisplatin versus gemcitabine plus cisplatin according to thymidylate synthase expression in nonsquamous non-small-cell lung cancer: a biomarker-stratified randomized phase II trial. J Clin Oncol 2015;33:2450-6.

42. Sun J, Han J, Ahn J, et al. Significance of thymidylate synthase and thyroid transcription factor 1 expression in patients with nonsquamous non-small cell lung cancer treated with pemetrexed-based chemotherapy. J Thorac Oncol 2011;6:1392-9.

43. Takezawa K, Okamoto I, Okamoto W, et al. Thymidylate synthase as a determinant of pemetrexed sensitivity in non-small cell lung cancer. Brit J Cancer 2011;104:1594-601.

44. Mou W, Xue H, Tong H. Prognostic value of serum leptin in advanced lung adenocarcinoma patients with cisplatin/pemetrexed chemotherapy. Oncol Lett 2014;7:2073-8.

45. Shi S, Wang M, Tian J. MicroRNA 25, microRNA 145, and microRNA 210 as biomarkers for predicting the efficacy of maintenance treatment with pemetrexed in lung adenocarcinoma patients who are negative for epidermal growth factor receptor mutations or anaplastic lymphoma kinase translocations. Transl Res 2016;170:1-7.

46. ClinicalTrials.Gov. Pemetrexed disodium and carboplatin in treating patients with recurrent ovarian, primary peritoneal or fallopian tube cancer. [Online]. Available from: https://clinicaltrials.gov/ct2/show/NCT01001910

47. ClinicalTrials.Gov. Methoxyamine, cisplatin, and pemetrexed disodium in treating patients with advanced solid tumors or mesothelioma that cannot be removed by surgery or mesothelioma that is refractory to pemetrexed disodium and cisplatin or carboplatin. [Online]. Available from: https://clinicaltrials.gov/show/NCT02535312

48. ClinicalTrials.Gov. Bosutinib in combination with pemetrexed in patients with selected metastatic solid tumors. [Online]. Available from: https://clinicaltrials.gov/show/NCT03023319

49. Schultz RM. Preclinical development of AlimtaTM (Pemetrexed, LY231514), a multitargeted antifolate. In: Herrling P.L., Matter A., Schultz R.M. (Eds.), Advances in targeted cancer therapy. Progress in Drug Research. Basel: Birkhauser; 2015. pp 63.

50. Rollins K, Lindley C. Pemetrexed: a multitargeted antifolate. Clin Ther 2005;27:1342-82.

51. Goldman I, Zhao R. Molecular, biochemical, and cellular pharmacology of pemetrexed. Semin Oncol 2002;29:3-17.

52. Adjei A. Pemetrexed (ALIMTA), A novel multitargeted antineoplastic agent. Clin Cancer Res 2004;10:4276s-80s.

53. Kano Y, Akutsu M, Tsunoda S, et al. Schedule-dependent interactions between pemetrexed and cisplatin in human carcinoma cell lines in vitro. Oncol Res 2006;16:85-95.

54. Bookman M, Brady M, McGuire W, et al. Evaluation of new platinum-based treatment regimens in advanced-stage ovarian cancer: a phase III trial of the Gynecologic Cancer InterGroup. J Clin Oncol 2009;27:1419-25. 